\title{
ELEMENTOS DO TRABALHO VOLUNTÁRIO: motivos e expectativas na pastoral da criança de João Pessoa/PB
}

\section{1- Carlos Eduardo Cavalcante*}

Doutorando em Administração pela Universidade Federal do Rio Grande do Norte (UFRN) Professor do Departamento de Administração da Universidade Federal da Paraíba (UFPB) cavalcanteeduardo@gmail.com http://lattes.cnpq.br/9223246246143138

\section{2- Washington José de Souza}

Doutorado em Educação pela Universidade Federal do Ceará (UFC)

Professor do Programa de Pós-Graduação em Administração da Universidade Federal do Rio Grande do Norte (UFRN) wsouza@ufrnet.br

http://lattes.cnpq.br/2387611219688981

\section{3- Abdon Silva Ribeiro da Cunha}

Mestrando do Programa de Pós-Graduação em Administração da Universidade Federal do Rio Grande do Norte (UFRN)

abdon_ribeiro@yahoo.com.br

http://lattes.cnpq.br/0207885895229580

\section{4- Marcos Adller de Almeida Nascimento}

Mestrando do Programa de Pós-Graduação em Administração da Universidade Federal do Rio Grande do Norte (UFRN)

adller_almeida@yahoo.com.br

http://lattes.cnpq.br/0390182192463372 


\title{
ELEMENTOS DO TRABALHO VOLUNTÁRIO: MOTIVOS E EXPECTATIVAS NA PASTORAL DA CRIANÇA DE JOÃO PESSOA/PB
}

\section{RESUMO}

O trabalho voluntário tem crescido expressivamente e possui um papel importante na sociedade. Assim, é importante delinear as motivações que levam voluntários a renunciarem ao benefício próprio, doando tempo e talentos em prol do outro. Este estudo tem por objetivo pesquisar os motivos e expectativas dos voluntários que atuam na Pastoral da Criança. Foi realizada com voluntários ligados a vinte e cinco paróquias de João Pessoa/PB distribuídas entre vários bairros desta cidade Por meio de 157 questionários. O instrumento de coleta de dados aplicado foi um questionário baseado em Souza, Medeiros e Fernandes (2006) e dividido em três seções. O tratamento dos dados foi feito a partir de medidas estatísticas (média e desvio-padrão) - na primeira seção - e utilização de percentagens - na segunda e terceira seções. Os perfis "afetivo" e "altruísta" predominam na realização do trabalho voluntário, caracterizando um voluntariado com interesse no resgate da cidadania e elevado grau de abnegação.

\section{Palavras-Chave}

Pastoral da Criança; trabalho voluntário; perfil.

\section{VOLUNTEERING ELEMENTS: REASONS AND EXPECTATIONS IN THE “PASTORAL DA CRIANÇA" AT JOÃO PESSOA/PB}

\begin{abstract}
Volunteer work has grown significantly and has had an important role in society. It is therefore important to establish the motivations that lead volunteers to give up their own good for the welfare of other people. Thus, this study aims at investigating the reasons and expectations of volunteers who work for the Pastoral da Criança. The survey was conducted among volunteers linked to twenty-five parishes in the city of João Pessoa. The data collection instrument was a questionnaire, based on Souza, Medeiros and Fernandes (2006). A hundred and fifty seven questionnaires were collected. The data was analysed, in the first section, using statistical measures (mean and standard deviation), and, in the second and third sections, using percentage. The "affective" and "selfless" profiles predominate in volunteer work, which characterises volunteers who are interested in the local recovery of citizenship and who have a high degree of selflessness.
\end{abstract}

\section{Keywords}

Pastoral da criança; volunteer work; profile. 


\section{Introdução}

O contexto do trabalho nos dias atuais está vinculado a uma série de mudanças. Tais intempéries incluem fenômenos, quais sejam: globalização; aumento da competitividade entre países e/ou em âmbito nacional (local); reestruturação produtiva; inovações tecnológicas; flexibilização das relações de trabalho; internacionalização dos mercados financeiros; dentre outras. Diante disso, temos que tanto o mercado de trabalho quanto as relações de trabalho são afetadas e estão em constante alteração.

O crescimento de organizações solidárias e sociais constitui-se como reflexo dos problemas enfrentados pela sociedade, especialmente, devido à crise de financiamento do Estado e ao simultâneo acirramento das relações de mercado. Neste sentido, essas organizações passam a executar políticas sociais que antes eram exclusividade do Estado. Em um contexto caracterizado por desigualdades, precarização do trabalho, desemprego, dentre outros fenômenos, o desenvolvimento das organizações sociais destina-se à redução de mazelas criadas pelo sistema vigente.

O trabalho voluntário remete a idéia de que se caracteriza por uma renúncia ao benefício próprio, em prol do interesse, do bem-estar e do desenvolvimento do outro e de coletividades, o que faz emergir a seguinte pergunta de pesquisa: Que perfis sugeridos pela Hierarquia dos 5 A's apresentam os voluntários da Pastoral da Criança de João Pessoa?

Assim o esforço desse trabalho é de partindo de características individuais, classificar os voluntários em determinadas categorias.

Concernente aos motivos da escolha do tema e a importância da pesquisa derivam as inquietações provenientes de interpretações e observações pessoais acerca do vínculo entre indivíduo e organização, principalmente na satisfação dos objetivos de cada um deles. Quanto melhor uma organização conhecer os trabalhadores voluntários melhor poderá responder às necessidades e expectativas destes indivíduos e atingir os objetivos definidos por esta. Por isso, compreender as motivações que podem levar um indivíduo a doar o seu tempo e conhecimento a uma determinada organização, sem esperar uma compensação monetária para realização de um serviço que traz benefícios ao próprio indivíduo e a terceiros, é relevante à Gestão Social.

O trabalho foi desenvolvido a partir da exploração da literatura existente na área e buscou conhecer motivações e expectativas dos voluntários que atuam na Pastoral da Criança. A pesquisa foi realizada junto a voluntários da Pastoral da Criança ligados a vinte e cinco paróquias da cidade de João Pessoa/PB distribuídas entre vários bairros desta cidade. Foi coletado um total de 157 questionários respondidos. $\mathrm{O}$ instrumento de coleta de dados aplicado foi um questionário de perguntas fechadas baseado em Souza, Medeiros e Fernandes (2006) e dividido em três seções. O tratamento dos dados foi feito a partir de medidas estatísticas (média e desvio-padrão) - na primeira seção - e utilização de percentagens - na segunda e terceira seções.

\section{Trabalho voluntário e o modelo dos 5 A's}

Nos dias atuais, estudos apontam que a maioria dos homens trabalha mesmo quando não precisa e as principais razões são: se relacionar com outras pessoas, ter sentimento de vinculação, ter algo para fazer, evitar o tédio ou ter um objetivo na vida (Morin, 2001). Hoje em dia o trabalho, diferentemente do significado negativo da antiguidade, é percebido de modo positivo pelo homem, além de possuir caráter libertador:

Para Codo (1992) o ser humano só se considera livre ao modificar o contexto em que vive e, portanto, o trabalho é meio de vida e, ao mesmo tempo, algo que o torna vivo, parecido consigo mesmo. Um outro prisma interessante é apresentado por Sen (2000) quando ressalta que as experiências de liberdade vividas pelo homem podem, em algum, momento associarem-se à substantividade de alguns aspectos, como por exemplo o modo como as pessoas vivem), e como consequência afastarem-se de concepções utilitaristas mais comuns, tais como as relacionadas à riqueza individual.

Fryer e Payne (apud Morin, 2001) destacam a diferença entre trabalho e emprego. Segundo os autores, o trabalho seria uma atividade útil, determinada por um objetivo definido que gera prazer na execução. Emprego seria, em tal entendimento, o conjunto de atividades remuneradas em um sistema organizado economicamente. O trabalho estaria mais relacionado a atividades compensatórias em si mesmas, enquanto que emprego estaria relacionado à compensação financeira, status e poder. Ramos (1989) 
prefere adotar diferenças entre trabalho e ocupação. Para o autor, "o trabalho é a prática de um esforço subordinada às necessidades objetivas inerentes ao processo de produção em si. A ocupação é a prática de esforços livremente produzidos pelo indivíduo em busca de sua atualização pessoal".

Dessa forma, a ação voluntária pode ser considerada trabalho, de acordo com Fryer e Payn (apud Morin, 2001), ou ocupação, no entendimento de Ramos, pois, é atividade que o indivíduo desenvolve com o objetivo de fazer algo útil e prazeroso, além de não-compulsória, não-remunerada, movida por valores como altruísmo, interesse próprio, sociabilidade, razões religiosas, afetivas ou aflitivas, resultantes de sentimentos de culpa ou de obrigação para com o outro, ou, ainda, pelo senso de responsabilidade.

No cerne do trabalho voluntário encontra-se o homem que disponibiliza tempo e competências no intuito de mudar a realidade. Para Dhome (2001), voluntário é a pessoa "que doa o seu trabalho, suas potencialidades e talentos em uma função que a desafia e gratifica em prol da realização de uma ação de natureza social".

Para Mostyn (1993) há cinco categorias de organizações voluntárias: altruístas; para ajudar pessoas em situação de aflição; para fornecer ajuda aos menos afortunados; para melhorar a sociedade; por interesse próprio. De comum nessas discussões, é evidente o entendimento de que a decisão para o trabalho voluntário varia entre motivos altruístas e interesses próprios, o que conduz à possibilidade de uma hierarquia.

Foi com base nesse entendimento que Souza, Medeiros e Fernandes (2006) traçaram uma Hierarquia de Valores atinentes ao Trabalho Voluntário, delimitada, em cada nível, pela distinção do valor da ação e por atitudes de sujeitos. Numa Hierarquia de 5A's são contemplados os seguintes níveis:

Figura 1: Hierarquia de Valores

\begin{tabular}{|c|c|c|}
\hline Níveis & Descrição \\
\hline Altruísta & $\begin{array}{r}\text { retrata a percepção subjetiva de auto-sacrifício por parte do voluntário, envolvendo risco, } \\
\text { insalubridade e periculosidade, sob a perspectiva da consciência de espécie ou de } \\
\text { questionamento em torno das condições gerais de vida de seres humanos. Nesse caso, há } \\
\text { uma consciência societal; }\end{array}$ \\
\hline Afetivo & $\begin{array}{r}\text { reúne motivos relativos ao sentimento de auxílio a sujeitos e comunidades em situações de } \\
\text { exceção, via fornecimento de apoio direto aos menos aptos e prósperos tais como idosos, } \\
\text { crianças, desabilitados e pacientes em hospitais, estando o voluntário interessado no } \\
\text { resgate da cidadania, numa perspectiva local; }\end{array}$ \\
\hline Amigável & $\begin{array}{c}\text { contempla motivos vinculados à avaliação subjetiva de contribuição para o bem-estar } \\
\text { social, e de desafortunados em particular, sob uma perspectiva amistosa, em que o } \\
\text { voluntário se sente compartilhando algo próprio com alguém em dado espaço } \\
\text { organizacional; }\end{array}$ \\
\hline Ajustado & $\begin{array}{r}\text { reúne motivos de uma forma específica de aprimoramento social não centrada em temas } \\
\text { cruciais ou aflitivos, mas que, de alguma forma, transmite ao voluntário a sensação de } \\
\text { estar, simultaneamente, promovendo a si próprio e a vida do receptor sob uma interação } \\
\text { grupal; }\end{array}$ \\
Ajuizado & $\begin{array}{c}\text { congrega motivos centrados na sensação de privilégios, de status e de proteção, estando o } \\
\text { voluntário interessado na construção e projeção da auto-imagem ou na promoção pessoal } \\
\text { junto a indivíduos e coletividades. Trata-se de um posicionamento centrado no eu, portanto, } \\
\text { egoísta em essência. }\end{array}$ \\
\hline
\end{tabular}

Fonte: Autor

Os motivos variam desde graus mais elevados, centrados no altruísmo, a um inferior, com viés egoísta. Não apenas motivos subjetivos distintos estão vinculados à tipologia do trabalho voluntário, mas, graus diferenciados e complementares de racionalidade substantiva e instrumental, conforme sugere a Figura 1.

As ações que caracterizam a racionalidade instrumental ocorrem a partir da ênfase nos fins, no cálculo, com o deliberado propósito de maximizar resultados. De outra forma, ações fundadas na racionalidade substantiva relacionam-se ao julgamento ético, orientadas por valores. Além disso diferente da racionalidade instrumental, caracterizada por uma visão utilitarista, a racionalidade substantiva trata do desenvolvimento humano, da promoção da consciência individual e da emancipação humana. (RAMOS, 1989).

Os níveis da escala, todavia, não servem para qualificar o valor do trabalho voluntário, mas, sim, tão somente para caracterizar os diversos perfis de sujeitos que por ele transitam.

Trata-se, portanto, de um exercício focado no comportamento organizacional, destinado à retroalimentação de processos de gestão da ação voluntária, envolvendo as fases de recrutamento, seleção, treinamento e desenvolvimento organizacional. 
Figura 2: Diagrama da Hierarquia dos 5 A's
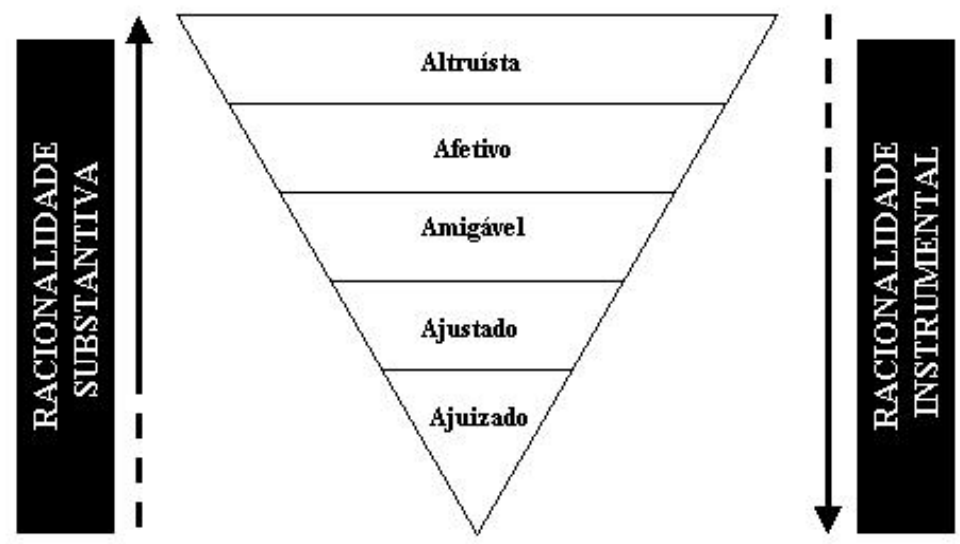

Fonte: elaborado a partir de Mostyn (1993)

\section{Metodologia}

No tocante aos aspectos metodológicos, esta pesquisa é caracterizada como descritiva, uma vez que busca compreender e descrever os motivos do trabalho voluntário na Pastoral da Criança. Segundo Vergara (1998) a pesquisa descritiva pretende descrever fatos e fenômenos da realidade. Em relação aos procedimentos, trata-se de uma pesquisa censitária. A pesquisa censitária como aquela que tem a pretensão de abranger a totalidade do universo sendo utilizada para populações pequenas (Vergara, 1998).

Este trabalho tem como ambiente de pesquisa a Pastoral da Criança, por meio dos seus voluntários, em João Pessoa/PB distribuídos entre vinte e cinco paróquias, alcançando 157 indivíduos de um número estimado de 250. A coleta de dados foi feita no momento da visita feita aos voluntários, nas Paróquias da cidade.

A Pastoral da Criança é organismo de ação social gerido pela Conferência Nacional dos Bispos do Brasil (CNBB). A proposta da organização é contribuir para a redução dos agravos a que estão submetidas as crianças brasileiras que vivem na pobreza, Por meio da coordenação de ações básicas de saúde, nutrição e educação. As ações desenvolvidas pela Pastoral agremiam um número significativo de pessoas. No tocante à representatividade da Instituição Igreja Católica, cotas de sacerdotes e religiosos se envolvem na atuação da organização, mas, vem de indivíduos do meio social a maior parcela de contribuição para o desenvolvimento das atividades inerentes à Pastoral da Criança, mediante a adesão ao trabalho voluntário.

No momento da aplicação, instrumento de coleta e caneta foram disponibilizados aos respondentes, e cerca de 10 voluntários necessitaram de auxílio na leitura e preenchimento dos dados. As visitas foram previamente agendadas e aconteceram no período da tarde, em dias diferentes em cada uma das Paróquias, durante os meses de setembro a dezembro de 2009.

O instrumento de coleta de dados utilizado foi um questionário com perguntas fechadas baseado em Souza, Medeiros e Fernandes (2006), é dividido em três seções: a primeira delineando o perfil do voluntário a partir dos fatores sugeridos - Altruísta, Afetivo, Amigável, Ajustado e Ajuizado - com respostas variando de "discordo totalmente" a "concordo totalmente"; a segunda com questões de conhecimentos gerais sobre diversos aspectos que envolvem a Pastoral da Criança; e a terceira é composta por questionamentos acerca do perfil sócio-demográfico dos respondes.

No que diz respeito à primeira seção do questionário, foi utilizada uma escala do tipo Likert (Hair; Anderson; Tathan \& Black, 2005) de cinco graus, variando de "discordo totalmente" a "concordo totalmente", foram abordados elementos do comportamento organizacional relacionados a motivos de "entrada", "expectativa", "permanência" e "saída" tomando como espaço de investigação a Pastoral da Criança. Quanto aos itens "entrada", "expectativas" e "permanência" estes estão associadas ao modelo dos 5 A's tendo sido calculados a média e o desvio-padrão associado a cada perfil e a cada questão.

De acordo com Mattar (2001), a média corresponde ao valor médio de um conjunto de dados, sendo uma medida de tendência central de aplicação exclusiva a variáveis intervalares. Segundo Barbin (2004), um aspecto importante no estudo descritivo de um conjunto de dados é a verificação da variabilidade ou 
dispersão dos dados, em relação à medida de localização central da amostra. Algumas medidas são: amplitude total, desvio padrão e coeficiente de variação.

Segundo Mattar (2001), a medida de dispersão mais simples de ser obtida é amplitude total. Esta medida é indicada para dados com dispersão acentuada. Para obter uma medida da variabilidade ou dispersão na mesma escala de mensuração dos dados, tomamos a raiz quadrada da variância e obtemos o desvio padrão. As características contidas no desvio-padrão são as seguintes: pode assumir somente valores positivos, quanto maior mais dispersos os dados (Mattar, 2001).

Já o item "saída" visa eleger os motivos de saída dos voluntários da pastoral que tem mais relevância. Visto não ter correlação com o modelo teórico dos 5 A's, foi incluída no intuito de se caracterizar os contornos do trabalho voluntário (entrada-permanencia-saída). Tendo em mãos a média e desvio-padrão foi executado a descrição destes dados. A Figura 3 auxilia nesta explicação.

Figura 3: Perfil dos voluntários e questões associadas

\begin{tabular}{|c|c|c|c|c|}
\hline \multicolumn{5}{|c|}{ Perfil dos Voluntários e Questões Associadas } \\
\hline $\begin{array}{l}\text { Perfil dos } \\
\text { voluntários }\end{array}$ & $\begin{array}{c}\text { Questões referentes } \\
\text { à entrada }\end{array}$ & $\begin{array}{c}\text { Questões referentes às } \\
\text { expectativas }\end{array}$ & $\begin{array}{c}\text { Questões referentes à } \\
\text { permanência }\end{array}$ & $\begin{array}{l}\text { Questões } \\
\text { referentes à saída }\end{array}$ \\
\hline Altruísta & 1 e 6 & 1 e 6 & 1 e 6 & - \\
\hline Afetivo & 2 e 7 & 2 e 7 & 2 e 7 & - \\
\hline Amigável & 3 e 8 & 3 e 8 & 3 e 8 & - \\
\hline Ajustado & 4 e 9 & 4 e 9 & 4 e 9 & - \\
\hline Ajuizado & 5 e 10 & 5 e 10 & 5 e 10 & - \\
\hline
\end{tabular}

Fonte: Elaborado pelo autor

Na segunda seção do questionário, as informações colhidas são de caráter geral sobre aspectos, tais como: de tempo de permanência, desistência da Pastoral, motivos que considera que os voluntários desistem da Pastoral. Algumas dessas questões foram de múltipla escolha e outras foram perguntas abertas. As questões referentes ao último bloco, perfil sócio demográfico, foram questões de múltipla escola e algumas questões foram abertas também.

O tratamento da segunda e terceira seção foi realizado por meio de percentagem e, a partir destas, realizou-se a descrição dos dados.

Quanto as segunda e terceira seções do questionário os dados foram tratados por meio de percentagem e, a partir destas, realizou-se a descrição dos dados.

Por se tratar de um trabalho de aplicação de uma ferramenta que ainda está no campo conceitual e para um melhor entendimento da análise de dados, o leitor deverá ter como referência para o entendimento da análise dos dados a Figura 3 em cada motivo discutido: entrada, expectativa, permanência e saída. Lá está a referência teórica que embasou as análises.

\section{Análise dos Dados}

A seguir, são apresentados os resultados da aplicação do questionário, divididos em três partes, conforme os objetivos específicos pretendidos.

\subsection{Entrada dos Voluntários na Pastoral da Criança}

Por meio dessa variável (entrada) buscou-se obter informações quanto às motivações que levaram os voluntários a entrar na Pastoral. Na tabela 1, abaixo, foi apresentado a média e o desvio padrão de cada questão da entrada e a média e o desvio-padrão associada a cada perfil.

Diante da tabela 1, é possível concluir que a maioria dos voluntários que entra na Pastoral da Criança apresenta o perfil "afetivo". Além disso, esse perfil apresenta um desvio padrão de 0,62 o que indica certa homogeneidade nas respostas, ou seja, que estas se encontram bem próximas da média, não havendo grande oscilação nas respostas obtidas.

No tocante à questão 2, a entrada está relacionada "a fazer algo importante" o que, no âmbito da Pastoral, se materializa fundamentalmente no auxílio direto à manutenção e/ou recuperação da saúde das crianças assistidas pela entidade e no resgate da dignidade humana, contribuindo também para que as 
crianças tenham uma vida mais saudável e possam ter uma melhor saúde física e, de forma indireta, psicológica.

Tabela 1: Média e Desvio Padrão dos Perfis relacionados à entrada dos voluntários

\begin{tabular}{|c|c|c|c|c|c|}
\hline Perfil & Questão & $\begin{array}{l}\text { Média da } \\
\text { Questão }\end{array}$ & $\begin{array}{l}\text { Desvio Padrão } \\
\text { da Questão }\end{array}$ & Média do Perfil & $\begin{array}{c}\text { Desvio Padrão do } \\
\text { Perfil }\end{array}$ \\
\hline \multirow{2}{*}{ Altruísta } & 1 & 4,30 & 0,63 & \multirow{2}{*}{4,04} & \multirow{2}{*}{0,72} \\
\hline & 6 & 4,50 & 0,67 & & \\
\hline \multirow{2}{*}{ Afetivo } & 2 & 4,42 & 1,13 & \multirow{2}{*}{4,43} & \multirow{2}{*}{0,72} \\
\hline & 7 & 4,44 & 1,14 & & \\
\hline \multirow{2}{*}{ Amigável } & 3 & 3,40 & 1,09 & \multirow{2}{*}{2,65} & \multirow{2}{*}{1,34} \\
\hline & 8 & 1,90 & 0,79 & & \\
\hline \multirow{2}{*}{ Ajustado } & 4 & 2,11 & 0,77 & \multirow{2}{*}{2,93} & \multirow{2}{*}{1,42} \\
\hline & 9 & 3,76 & 1,10 & & \\
\hline \multirow{2}{*}{ Ajuizado } & 5 & 3,73 & 1,18 & \multirow{2}{*}{3,94} & \multirow{2}{*}{1,01} \\
\hline & 10 & 4,16 & 0,87 & & \\
\hline
\end{tabular}

Fonte: Dados da pesquisa, 2010

Figura 4: Legenda referente às questões de 1 a 10 em relação à entrada dos voluntários na Pastoral da Criança

\begin{tabular}{|c|c|c|}
\hline \multirow{11}{*}{$\begin{array}{l}\mathrm{L} \\
\mathrm{E} \\
\mathrm{G} \\
\mathrm{E} \\
\mathrm{N} \\
\mathrm{D} \\
\mathrm{A}\end{array}$} & Questões & Entrada \\
\hline & 1. & Entrei na Pastoral para levar conhecimento aos assistidos. \\
\hline & 2. & Entrei na Pastoral para fazer algo importante. \\
\hline & 3. & Entrei na Pastoral para conhecer novas pessoas. \\
\hline & 4. & Entrei na Pastoral por curiosidade. \\
\hline & 5. & Entrei na Pastoral para me sentir bem. \\
\hline & 6. & Entrei na Pastoral porque quero um mundo melhor. \\
\hline & 7. & Entrei na Pastoral porque me identifico com o trabalho. \\
\hline & 8. & Entrei na Pastoral para participar de passeios, festas e fazer amizade. \\
\hline & 9. & Entrei na Pastoral para me desenvolver como pessoa. \\
\hline & 10. & Entrei na Pastoral para aprender. \\
\hline
\end{tabular}

Fonte: Questionário aplicado

Em se tratando do indicador 7, ainda associada ao perfil "afetivo", a entrada se dá porque "há identificação com o trabalho", ou seja, a realização das atividades relacionadas à Pastoral - recuperação de crianças por meio do fornecimento de alimentos; avaliar o peso da criança comparando-o ao padrão ideal de saúde; sensação de dever social cumprido; prazer em lidar com crianças e vê-las em melhores condições de dignidade humana; o resultado que o seu trabalho voluntário trará a curto, médio e longo prazo para a saúde física e mental das crianças assistidas; a alegria das famílias assistidas em ver a recuperação de seus filhos - contribuem para a satisfação pessoal e, intrinsecamente, é a identificação com o trabalho desenvolvido.

Assim pode ser dito que os voluntários pretendem, ao entrar na Pastoral, dar apoio direto aos menos aptos, aqui às crianças atendidas, porém em uma perspectiva local, em cada bairro.

Por outro lado, a menor média corresponde ao perfil "amigável", onde o desvio-padrão correspondente foi de 1,34, indicando uma maior heterogeneidade nas respostas. As respostas obtidas oscilaram bastante em torno dessa média. Estão relacionadas a esse perfil as questões 3 e 8.

A questão 3 versa sobre a entrada para "conhecer novas pessoas" e apresentou a menor média do perfil, ou seja, conhecer novas pessoas não é prioridade para entrada na Pastoral. Já a questão 8 disserta que a entrada na Instituição é para participar de "festas, passeios e fazer amizade", o que, tomando por base a média do perfil - o que foi a menor dentre os cinco possíveis perfis - entende-se que festas, passeios e fazer amizade também não é motivação para engajar-se na Pastoral. 
Nesse sentido percebe-se que o voluntário, nos motivos de "entrada", parece assumir um perfil mais altruísta, pois apresenta com maior média os perfis "afetivo" e "altruísta" e menor os perfis "amigável" e "ajustado". Entretanto o perfil "ajuizado", classificado como mais egoísta no continuum considerado para esta pesquisa, obteve a terceira maior média o que pode ser um indício de indefinição por parte dos voluntários em torno do motivo que o estimulou a entrada na Pastoral, se egoísta ou altruísta. Apesar disto deve ser lembrado que perfis altruístas receberam as maiores médias.

\subsection{Expectativas dos voluntários na Pastoral da Criança}

Por meio dessa variável (expectativas) buscou-se obter informações quanto à percepção dos voluntários em torno do que esperam alcançar com o trabalho desenvolvido na Pastoral. A tabela 2, apresentada abaixo, contém a média e o desvio-padrão de cada questão das expectativas e a média e o desvio padrão associada a cada perfil.

Tabela 2: Média e desvio padrão dos perfis relacionados com as expectativas dos voluntários

\begin{tabular}{|c|c|c|c|c|c|}
\hline \multicolumn{6}{|c|}{ Média e Desvio Padrão dos Perfis Relacionados com as Expectativas dos Voluntários } \\
\hline Perfil & Questão & $\begin{array}{l}\text { Média da } \\
\text { Questão }\end{array}$ & $\begin{array}{c}\text { Desvio Padrão } \\
\text { da Questão }\end{array}$ & $\begin{array}{l}\text { Média do } \\
\text { Perfil }\end{array}$ & $\begin{array}{c}\text { Desvio Padrão do } \\
\text { Perfil }\end{array}$ \\
\hline \multirow{2}{*}{ Altruísta } & 1 & 4,68 & 0,61 & \multirow{2}{*}{4,51} & \multirow{2}{*}{0,76} \\
\hline & 6 & 4,39 & 0,86 & & \\
\hline \multirow{2}{*}{ Afetivo } & 2 & 4,68 & 0,58 & \multirow{2}{*}{4,65} & \multirow{2}{*}{0,61} \\
\hline & 7 & 4,62 & 0,63 & & \\
\hline \multirow{2}{*}{ Amigável } & 3 & 4,12 & 0,66 & \multirow{2}{*}{4,16} & \multirow{2}{*}{0,80} \\
\hline & 8 & 4,20 & 0,91 & & \\
\hline \multirow{2}{*}{ Ajustado } & 4 & 4,38 & 0,74 & \multirow{2}{*}{4,37} & \multirow{2}{*}{0,73} \\
\hline & 9 & 4,61 & 0,71 & & \\
\hline \multirow{2}{*}{ Ajuizado } & 5 & 3,66 & 1,11 & \multirow{2}{*}{4,00} & \multirow{2}{*}{1,02} \\
\hline & 10 & 4,33 & 0,73 & & \\
\hline
\end{tabular}

Fonte: Dados da pesquisa, 2010

Figura 5: Legenda referente às questões de 1 a 10 em relação às expectativas dos voluntários na Pastoral

\begin{tabular}{|l|c|l|}
\hline \multirow{4}{*}{} & Questões & \\
\cline { 2 - 3 } & 1. & Espero recuperar crianças com o meu trabalho na Pastoral. \\
\cline { 2 - 3 } $\mathrm{E}$ & 2. & Espero contribuir para que as mães tenham partos tranqüilos e não abortem. \\
\cline { 2 - 3 } $\mathrm{G}$ & 3. & Espero fazer amizades. \\
\cline { 2 - 4 } $\mathrm{E}$ & 4. & Espero adquirir conhecimento com meu trabalho na Pastoral. \\
$\mathrm{N}$ & 5. & Espero realização pessoal com o trabalho que presto na Pastoral. \\
$\mathrm{D}$ & 6. & Espero resgatar a dignidade humana com meu trabalho na Pastoral. \\
\cline { 2 - 4 } & 7. & Espero obter bons resultados para a saúde dos assistidos. \\
\cline { 2 - 4 } & 8. & Espero obter mais amor e carinho das famílias assistidas. \\
\cline { 2 - 4 } & 9. & Espero ter a sensação de dever cumprido com meu trabalho na Pastoral. \\
\cline { 2 - 4 } & 10. & Espero que o meu trabalho na Pastoral me ajude a lidar melhor com crianças. \\
\hline
\end{tabular}

Fonte: Questionário aplicado

Frente às informações contidas na tabela 2 a maioria dos voluntários apresenta expectativas associadas ao perfil "afetivo". Esse perfil apresenta um desvio padrão de 0,42, indicando certa homogeneidade nas respostas, ou seja, que estas se encontram bem próximas da média, não havendo grande oscilação nas respostas obtidas (da graduação de 1 a 5), em torno da média.

Dentro deste perfil, encontram-se as questões 2 e 7 (descritas na legenda da Figura 5). Quanto à questão 2, as expectativas relacionam-se com a contribuição “para que as mães tenham partos tranqüilos e não abortem", o que, na esfera da Pastoral, se dá Por meio do acompanhamento e visitas às famílias e 
mães grávidas assistidas pela Pastoral com instrução em aspectos alimentares, amamentação do bebê, possíveis doenças, profilaxias, questões higiênicas, entre outras - recomendações que se encontram no "Guia do líder" - e orientações no acompanhamento profissional em saúde e informações necessárias às gestantes e mães. Este indicador teve a maior média e o menor desvio-padrão o que reforça a homogeneidade da média alcançada: 4,68.

A questão 7, ainda associada ao perfil "afetivo", diz respeito à obtenção de "bons resultados para a saúde dos assistidos", ou seja, Por meio do acompanhamento das famílias e da obtenção de informações em assuntos pertinentes à saúde tais como - higiene, alimentação, prevenção e tratamento de doenças, cuidados com o bebê e crianças, entre outros - contribuem assim, para a diminuição da mortalidade infantil, buscando atingir resultados positivos e palpáveis aos assistidos concernentes à saúde destes.

O perfil "ajuizado", que obteve a menor média, indicando que estas expectativas estão em menor escala de interesse pelos voluntários e apresentou desvio-padrão correspondente a 1,02, apontando para certa heterogeneidade nas respostas, ou seja, as respostas obtidas oscilaram bastante em torno da média desse perfil. Tais resultados estão associados às questões 5 e 10. A questão 5 versa sobre "realização pessoal com o trabalho desenvolvido na Pastoral" o que se entende não ser tão relevante quanto às outras expectativas.

Já a questão 10 versa sobre a expectativa de que o trabalho desenvolvido na Pastoral contribua para um melhor tratamento no "lidar com as crianças", isto é, nas atividades desenvolvidas proporcionando um aprendizado e melhoramento na prática de tratar as crianças. No entanto, tomando por base a média do perfil - a qual foi a menor dentre os cinco possíveis perfis, compreende-se que esta expectativa não é tão importante para os voluntários. Não que seja dispensável - visto que a média desta questão foi 4,33 (estando entre a escala concordo e concordo totalmente) e o desvio padrão 0,73 - mas tão somente ocupando uma expectativa de nível geral inferior em relação às outras.

As expectativas também parecem estar em um nível mais altruísta, haja vista que as maiores médias se encontram entre os níveis "afetivo" e "altruísta". Por outro lado, os outros perfis obtiveram médias iguais ou maiores que 4, reforçando a tendência percebida nos motivos de entrada (1ạ análise) dos voluntários de que, apesar de demonstrarem fortemente motivos altruístas, também apresentam motivos egoístas.

\subsection{Permanência dos voluntários na Pastoral da Criança}

A utilização desta variável (permanência) deveu-se à intenção de obter informações quanto à percepção dos voluntários nas motivações relacionadas à permanência na Pastoral. A tabela 3, representada a seguir, demonstra a média e o desvio padrão de cada questão de permanência e a média e o desvio padrão associado a cada perfil.

Tabela 3: Média e desvio padrão dos perfis relacionados com a permanência dos voluntários

Média e Desvio Padrão dos Perfis Relacionados com a Permanência dos Voluntários

\begin{tabular}{|c|c|c|c|c|c|}
\hline Perfil & Questão & $\begin{array}{l}\text { Média da } \\
\text { Questão }\end{array}$ & $\begin{array}{c}\text { Desvio Padrão da } \\
\text { Questão }\end{array}$ & $\begin{array}{l}\text { Média do } \\
\text { Perfil }\end{array}$ & $\begin{array}{c}\text { Desvio Padrão do } \\
\text { Perfil }\end{array}$ \\
\hline \multirow{2}{*}{ Altruísta } & 1 & 4,66 & 0,51 & \multirow{2}{*}{4,53} & \multirow{2}{*}{0,67} \\
\hline & 6 & 4,40 & 0,78 & & \\
\hline \multirow{2}{*}{ Afetivo } & 2 & 4,20 & 0,84 & \multirow{2}{*}{4,21} & \multirow{2}{*}{0,78} \\
\hline & 7 & 4,22 & 0,73 & & \\
\hline \multirow{2}{*}{ Amigável } & 3 & 4,33 & 0,72 & \multirow{2}{*}{4,44} & \multirow{2}{*}{0,65} \\
\hline & 8 & 4,55 & 0,57 & & \\
\hline \multirow{2}{*}{ Ajustado } & 4 & 4,48 & 0,58 & \multirow{2}{*}{4,40} & \multirow{2}{*}{0,61} \\
\hline & 9 & 4,32 & 0,63 & & \\
\hline \multirow{2}{*}{ Ajuizado } & 5 & 4,12 & 0,71 & \multirow{2}{*}{4,12} & \multirow{2}{*}{0,78} \\
\hline & 10 & 4,11 & 0,84 & & \\
\hline
\end{tabular}

Fonte: Dados da pesquisa, 2010 
Elementos do trabalho voluntário:

motivos e expectativas na pastoral da criança de João Pessoa/PB

Figura 6: Legenda referente às questões de 1 a 10 em relação à permanência dos voluntários na Pastoral

\begin{tabular}{|c|c|c|}
\hline \multirow{11}{*}{$\begin{array}{l}\mathrm{L} \\
\mathrm{E} \\
\mathrm{G} \\
\mathrm{E} \\
\mathrm{N} \\
\mathrm{D} \\
\mathrm{A}\end{array}$} & Questões & Permanência \\
\hline & 1. & O que me mantém na Pastoral é o amor ao próximo. \\
\hline & 2. & O que me mantém na Pastoral é a situação das crianças. \\
\hline & 3. & A força de vontade é o que me mantém na Pastoral. \\
\hline & 4. & O que me mantém na Pastoral é o amor que tenho pelas crianças. \\
\hline & 5. & O que me mantém na Pastoral é o gosto por fazer as atividades. \\
\hline & 6. & Permaneço na Pastoral por um gesto de fé. \\
\hline & 7. & Permaneço na Pastoral por causa do envolvimento com as famílias e com as crianças. \\
\hline & 8. & Permaneço na Pastoral para ajudar as famílias. \\
\hline & 9. & Permaneço na Pastoral para transmitir conhecimento para as famílias. \\
\hline & 10. & Permaneço na Pastoral porque tenho a oportunidade de aprender a lidar com crianças. \\
\hline
\end{tabular}

Fonte: Questionário aplicado

Considerando a tabela 3 nota-se que a maior parte dos voluntários permanece na Pastoral da Criança por motivos "altruístas". Para reforçar essa informação, esse perfil apresenta um desvio padrão de 0,67, o que indica que a oscilação da respostas em torno dessa média foi pequena, ou seja, as respostas foram razoavelmente homogêneas.

Associado a este perfil estão as questões 1 e 6 . A questão 1 relaciona a permanência na Pastoral com o "amor ao próximo" o que significa que os voluntários têm por base de permanência pelo amor que sente pelos assistidos de tal maneira que, apesar de dificuldades enfrentadas no trabalho desenvolvido - risco, insalubridade, periculosidade, falta de recursos e apoio governamental, número reduzido de voluntários - é o amor incondicional que faz com que eles permaneçam na Instituição, desenvolvendo seu trabalho com dedicação e solidariedade, visando à recuperação dos assistidos e melhores condições de vida para estes e, conseqüentemente, para a sociedade.

Já a questão de número 6, ainda associada ao perfil "altruísta", diz respeito à permanência na Pastoral como "gesto de fé", ou seja, é Por meio do trabalho desenvolvido junto a famílias carentes, visando ao desenvolvimento integral da criança (da concepção aos seis anos de idade) e, por conseqüência, suas famílias e comunidades, auxiliando na redução do índice de mortalidade infantil e desnutrição, combatendo a marginalidade social, praticando assim a justiça, a retidão, a caridade, o amor ao próximo, valores cristãos, que buscam professar a fé em Deus.

Do outro lado, o perfil "ajuizado" obteve a menor média, dando a entender que a permanência na Pastoral não está de acordo com o que versa este perfil - o mais egoísta. Entretanto, apesar de ser a menor média, esta ainda ficou acima de 4, o que demonstra existir respostas com perfis egoístas. Quanto ao desvio-padrão, de 0,78, fica indicado certo nível de dispersão em torno da média, mas não descaracteriza o resultado.

Correspondem a este perfil as questões 5 e 10. A primeira afirma que a permanência na Pastoral é devido ao "gosto por fazer as atividades" e, a segunda, por ser "a oportunidade de aprender a lidar com crianças".

\subsection{Saída de voluntários na Pastoral da Criança}

O uso desta variável (saída) teve por finalidade conseguir informações da percepção dos voluntários quanto às motivações relacionadas à saída da Pastoral. A tabela 4, apresentada a seguir, contém a média e o desvio padrão de cada questão associada à saída. É válido destacar que as respostas são graduadas de "discordo totalmente" - equivalente ao número 1 - a "concordo totalmente" - equivalente ao número 5 . Os voluntários, neste item, indicaram possíveis motivos que os levariam a sair da pastoral.

A partir dos dados da Figura 6, percebe-se que o motivo que levaria um voluntário a deixar as atividades da Pastoral seria problema de saúde, pois, esta variável apresentou a maior média 3,33. Isso significa que caso o voluntário venha a enfrentar problemas de saúde há forte tendência de ele sair da Pastoral. O desvio-padrão associado a esta média equivale a 1,18 o indica que as respostas oscilaram em torno da média. 
Tabela 4: Média e Desvio Padrão das questões relacionadas à saída dos voluntários

Média e Desvio Padrão das Questões Relacionadas à Saída dos Voluntários

\begin{tabular}{c|l|l}
\hline 1 & 1,69 & 0,93 \\
\hline 2 & 2,04 & 1,08 \\
\hline 3 & 1,71 & 0,85 \\
\hline 4 & 2,37 & 1,38 \\
\hline 5 & 2,17 & 1,30 \\
\hline 6 & 2,25 & 1,22 \\
\hline 7 & 2,54 & 1,25 \\
\hline 8 & 2,27 & 1,23 \\
\hline 9 & 1,97 & 1,04 \\
\hline 10 & 3,33 & 1,18 \\
\hline 11 & 2,14 & 1,16 \\
\hline 12 & 2,33 & 1,19 \\
\hline 13 & 1,95 & 0,96 \\
\hline 14 & 2,05 & 1,09 \\
\hline
\end{tabular}

Fonte: Dados da pesquisa, 2011

Os demais motivos ficaram abaixo de 2,5 de média, demonstrando que poucos motivos fariam o voluntário deixar a atividade na Pastoral.

Neste sentido, se destaca o indicador 1 ("Eu sairia se a Pastoral não tivesse mais recursos.") com a menor entre as questões (1,69). A partir desta média entende-se que mesmo considerando que os recursos disponibilizados pela entidade são escassos, os voluntários, ainda assim, não se mostram propensos a sair por esse motivo. Isto ocorre porque, mesmo com poucos recursos fornecidos, em comum acordo, reúnemse e buscam suprir tal escassez por meio de recursos próprios. Além disso, considera-se que o trabalho voluntário realizado demanda quantidade restrita de recursos financeiros, inclusive por não haver qualquer tipo de pagamento ao pessoal, à exceção de auxílio para deslocamento. O desvio-padrão desta questão consta de 1,12, dando a entender que houve uma oscilação considerável nas respostas dos voluntários, indicando que estes percebem a questão abordada de forma diferente, ou seja, têm opiniões diferentes, mas, em média, discordam em sair da instituição em caso da falta de recursos.

Figura 7: Legenda referente às questões de 1 a 14 em relação à saída dos voluntários na Pastoral

\begin{tabular}{|c|c|c|}
\hline \multirow{15}{*}{$\begin{array}{l}\mathrm{L} \\
\mathrm{E} \\
\mathrm{G} \\
\mathrm{E} \\
\mathrm{N} \\
\mathrm{D} \\
\mathrm{A}\end{array}$} & Questões & Saída \\
\hline & 1. & Eu sairia se a Pastoral não tivesse mais recursos. \\
\hline & 2. & Eu sairia da Pastoral por falta de voluntários. \\
\hline & 3. & Eu sairia da Pastoral por falta de apoio governamental. \\
\hline & 4. & Eu sairia da Pastoral caso perdesse a fé em Deus. \\
\hline & 5. & Eu sairia da Pastoral por falta de amor ao próximo. \\
\hline & 6. & Eu sairia da Pastoral por falta de Coordenação. \\
\hline & 7. & Eu sairia se houvesse descontinuidade nos trabalhos da Pastoral. \\
\hline & 8. & Eu sairia da Pastoral por falta de tempo. \\
\hline & 9. & Eu sairia da Pastoral por falta de ânimo para fazer o trabalho. \\
\hline & 10. & Eu sairia da Pastoral por problemas de saúde. \\
\hline & 11. & Eu sairia da Pastoral se houvesse desinteresse das mães assistidas. \\
\hline & 12. & Eu sairia se fosse residir em um bairro que não tenha Pastoral. \\
\hline & 13. & Eu sairia se houvesse mudança na estrutura de funcionamento da Pastoral. \\
\hline & 14. & Eu sairia pelo aumento da minha carga de trabalho. \\
\hline
\end{tabular}

Fonte: Questionário aplicado

Outra afirmação "Eu sairia da Pastoral por falta de apoio governamental." Também obteve média baixa, 1,71, o que significa dizer que, mesmo não havendo auxílio do governo, os voluntários, de modo geral, consideram que isto não é fator decisivo para deixar o trabalho. Para estes, o apoio do governo é 
importante, mas, não essencial para que o trabalho permaneça em evidência e assim a ausência de apoio governamental não é causa para desligamento.

\section{Conclusão}

Neste trabalho se buscou conhecer que perfis assumem os voluntários da Pastoral da Criança em João Pessoa/PB na entrada, na permanência, nas expectativas e na saída da atividade voluntária.

O trabalho voluntário é caracterizado por uma renúncia ao benefício próprio, em que o voluntário doa o tempo, potencialidades e talentos em prol do interesse, do bem-estar e do desenvolvimento do outro e de coletividades, ou seja, em proveito da realização de uma ação de natureza solidária.

Predominam os perfis "afetivo" e "altruísta", caracterizando um voluntariado com motivos e sentimentos de auxílio a sujeitos e comunidades em situações de exceção, estando o voluntário interessado no resgate da cidadania, numa perspectiva local e com elevado grau de abnegação, envolvendo o auto-sacrifício para promoção do bem-estar da sociedade.

A maior parte dos voluntários (correspondente a 90\%) entrou e permanece na Pastoral da Criança, por período superior a 5,5 anos, em média. Considerando a desistência, uma percentagem expressiva dos voluntários (equivalente a $87 \%$ ) conhece algum voluntário que desistiu do trabalho e o fator "falta de tempo" obteve $31 \%$ como influenciador dessa decisão. Cerca de $43 \%$ dos voluntários acreditam que o que explicaria a desistência de voluntários seria o desinteresse ou a falta de identificação com o trabalho. Nesse caso, como o voluntário entra na Pastoral por pensar que se identifica com o trabalho e, ao estar engajado na Pastoral, percebe que efetivamente não se identificou com o trabalho, a maioria (equivalente a $43 \%$ ) prefere sair.

Uma percentagem expressiva dos voluntários (equivalente a 93\%) mora na comunidade em que atua na Pastoral da Criança. Porém, caso haja a descontinuidade do trabalho da Pastoral naquele bairro há forte tendência para a saída, visto que a "descontinuidade do trabalho da Pastoral" foi o terceiro maior fator de inclinação para saída. Quanto à escolaridade não há relação direta entre esta e a entrada, a permanência ou a saída da Pastoral da Criança visto não ser necessário qualquer conhecimento advindo do sistema de educação formal para desempenher a atividade. Aproximadamente $60 \%$ dos voluntários têm renda familiar até dois salários mínimos e, embora escassos recursos, a maior parte afirmou que não sairia.

Concernente à ocupação "dona de casa" predomina maior flexibilidade no gerenciamento do tempo quanto à distribuição entre as atividades do lar e o trabalho desenvolvido junto à Pastoral. Vale lembrar que "falta de tempo" foi a sexta média com indicação para a saída da Pastoral.

Assim, a necessidade de reconhecer os motivos que conduzem um indivíduo a se voluntariar e a se manter nesta atividade pode ter relevância tanto acadêmica quanto às organizações. Para a academia este estudo apresenta a possibilidade de validação de construção de um instrumento quantitativo de identificação de motivos de entrada, de permanência, de expectativas e de saída de voluntários em âmbito nacional.

Tal esforço se justifica, pois após pesquisa em dois banco de dados digitais brasileiros, o Domínio Publico e a Biblioteca Digital de Teses e Dissertações (que agrupam cerca de 101 universidades nacionais), além da pesquisa entre periódicos classificados no Qualis (entre A1 e B5) e no sítio da Anpad, pesquisa buscando trabalhos que continham ou no seu titulo ou palavras-chave os termos: Voluntário; Voluntariado; Terceiro Setor, que foram definidas como norteadoras por refletirem com alguma exatidão o que se quer conhecer: a motivação no trabalho voluntário em instituições sem fins lucrativos, chegou-se a 562 trabalhos.

Após uma leitura mais detalhada dos resumos foram identificados 20 trabalhos que atendiam esta característica. Nenhum desses estudos usa metodologias quantitativas para a coleta de dados.

Ainda deve ser considerado que este o instrumento de coleta de dados está na sua primeira versão e necessita ainda de maior refinamento, apesar de ter alcançado bom índice de confiabilidade. Para tal constatação foi usado o Alpha de Cronbach que é um coeficiente de consistência, que alcançou valores entre 0,71 e 0,80, em cada motivo: entrada, permanência, expectativas e saída. É nesse tema, portanto, que está a direção que os próximos estudos deverão seguir: refinamento do instrumento, por meio do aumento de indicadores em cada motivo e nova coleta e análise de dados. 
Para as organizações pode auxiliar na gestão do voluntariado, sem ter a pretensão de esgotar a reflexão sobre este tema, pois conforme Bussell e Forbes (2002) na Europa e Gaskin (1998), nos EUA destacam que as instituições tem tido dificuldades no recrutamento e manutenção dos seus voluntários.

Para a Pastoral deve será dada uma maior atenção à manutenção das paróquias nos bairros que atuam as voluntárias, visto que, a inexistência de uma paróquia no bairro que atua, é um motivo de saída. Mas verificar a possibilidade de um acompanhamento da saúde das voluntárias parece ser a principal medida a adotar para evitar, ou mesmo, diminuir, a saída da voluntárias, pois este é o principal motivo de suas saídas.

\section{Referências}

Barbin, D.(2004). Componentes de variância: teoria e aplicações. Piracicaba: FEALQ.

Bussell, H \& Forbes, D. (2002). Understanding the volunteer market: The what, where, who and why of volunteering. International journal of Nonprofit and Voluntary Sector Marketing, 7 (3), pp. $244-257$.

Codo, W. (1992). O que é alienação. São Paulo: Brasiliense.

Dohme, V. D. (2001). Voluntariado - equipes produtivas: como liderar ou fazer parte de uma delas. São Paulo: Editora Mackenzie.

Gaskin, K. (1998). Vanishing volunteers: Are young people losing interest in volunteering? Voluntary Action, 1(1), 33-43

Hair, J.F. Jr., Anderson, R.E., Tathan, R.L. \& Black, W.C.(2005). Análise Multivariada de Dados (5a ed.). Porto Alegre: Bookman.

Mattar, F. N. (2001). Pesquisa de Marketing. São Paulo: Atlas.

Morin, Estelle (2001). Os sentidos do trabalho. Revista de Administração de Empresas, 41 (3), p.10, jul/set.

Mostyn, B. (1993). The meaning of volunteer work: a qualitative investigation. In: Hatch, S. (Org.). Volunteers: patterns, meanings \& motives. Hertz (Reino Unido): The Volunteer Centre.

Ramos, A. G. (1989). A nova ciência das organizações: uma reconceituação da riqueza das nações (2a ed.). Rio de Janeiro: FGV.

Sen, A. K. (2000). Desenvolvimento como liberdade. São Paulo: Companhia das Letras.

Souza, W. J.; Medeiros, J. P. de e Fernandes, C. L. (2006). Trabalho voluntário: elementos para uma tipologia. In: Anais do Colóquio Internacional sobre Poder Local, Salvador, BA, Brasil, 10.

Vergara, S. C. (1998). Projetos e relatórios de pesquisa em administração. São Paulo: Atlas. 